\title{
Use of ciliate and phytoplankton taxonomic composition for the estimation of eicosapentaenoic acid concentration in lakes
}

\author{
MELANIE HARTWICH*, DIETMAR STRAILE ${ }^{\dagger}$, URSULA GAEDKE* AND ALEXANDER WACKER* \\ *Institute of Biochemistry and Biology, University of Potsdam, Potsdam, Germany \\ ${ }^{+}$Limnological Institute, University of Constance, Konstanz, Germany
}

\section{SUMMARY}

1. The polyunsaturated fatty acid eicosapentaenoic acid (EPA) plays an important role in aquatic food webs, in particular at the primary producer-consumer interface where keystone species such as daphnids may be constrained by its dietary availability. Such constraints and their seasonal and interannual changes may be detected by continuous measurements of EPA concentrations. However, such EPA measurements became common only during the last two decades, whereas long-term data sets on plankton biomass are available for many well-studied lakes. Here, we test whether it is possible to estimate EPA concentrations from abiotic variables (light and temperature) and the biomass of prey organisms (e.g. ciliates, diatoms and cryptophytes) that potentially provide EPA for consumers.

2. We used multiple linear regression to relate size- and taxonomically resolved plankton biomass data and measurements of temperature and light intensity to directly measured EPA concentrations in Lake Constance during a whole year. First, we tested the predictability of EPA concentrations from the biomass of EPA-rich organisms (diatoms, cryptophytes and ciliates). Secondly, we included the variables mean temperature and mean light intensity over the sampling depth $(0-20 \mathrm{~m})$ and depth $(0-8$ and $8-20 \mathrm{~m})$ as factors in our model to check for large-scale seasonal- and depth-dependent effects on EPA concentrations. In a third step, we included the deviations of light and temperature from mean values in our model to allow for their potential influence on the biochemical composition of plankton organisms. We used the Akaike Information Criterion to determine the best models.

3. All approaches supported our proposition that the biomasses of specific plankton groups are variables from which seston EPA concentrations can be derived. The importance of ciliates as an EPA source in the seston was emphasised by their high weight in our models, although ciliates are neglected in most studies that link fatty acids to seston taxonomic composition. The large-scale seasonal variability of light intensity and its interaction with diatom biomass were significant predictors of EPA concentrations. The deviation of temperature from mean values, accounting for a depth-dependent effect on EPA concentrations, and its interaction with ciliate biomass were also variables with high predictive power.

4. The best models from the first and second approaches were validated with measurements of EPA concentrations from another year (1997). The estimation with the best model including only biomass explained $80 \%$, and the best model from the second approach including mean temperature and depth explained $87 \%$ of the variability in EPA concentrations in 1997.

5. We show that it is possible to predict EPA concentrations reliably from plankton biomass, while the inclusion of abiotic factors led to results that were only partly consistent with expectations

Correspondence: Melanie Hartwich, Institute of Biochemistry and Biology, University of Potsdam, Am Neuen Palais 10, D-14469 Potsdam, Germany. E-mail: melanie.hartwich@uni-potsdam.de 
from laboratory studies. Our approach of including biotic predictors should be transferable to other systems and allow checking for biochemical constraints on primary consumers.

Keywords: ciliates, diatoms, eicosapentaenoic acid, light, temperature

\section{Introduction}

The polyunsaturated fatty acid eicosapentaenoic acid (EPA) was found to be one of the most important biochemical food components in freshwater food webs (Ahlgren et al., 1990; Müller-Navarra, 1995a; Kainz, Arts \& Mazumder, 2004). In laboratory and field studies, EPA was found to be important for growth and reproduction of daphnids, one of the main freshwater herbivores (Von Elert, 2002; Wacker \& Martin-Creuzburg, 2007; Hartwich et al., 2012). Unlike algae, planktonic herbivores such as daphnids are not able to synthesise EPA de novo or only at an extremely low rate. Hence, their supply of this essential resource largely depends on their food (Beenakkers, Van der Horst \& Van Marrewijk, 1985). Studies using seston as food for Daphnia have shown that sestonic EPA concentrations are highly significant predictors of Daphnia somatic growth rates. This is because the concentration of EPA per litre combines quantitative (the amount of food) and qualitative (the EPA content of food) aspects of the food of herbivores. Daphnids feed indiscriminately on seston up to a size of approximately 30-50 $\mu \mathrm{m}$ depending on their body size (Burns, 1968). The food of daphnids therefore consists of bacteria, autotrophic picoplankton, phytoplankton, heterotrophic nanoflagellates and small ciliates. Some taxa (cyanobacteria, chlorophytes) usually contain no or only small amounts of EPA (Ahlgren, Gustafsson \& Broberg, 1992). The main EPA sources in the seston food of daphnids are chrysophytes, dinophytes, diatoms and cryptophytes, which are all rich in EPA (Beach, Harrington \& Holz, 1970; Ahlgren et al., 1990; Kainz et al., 2009). Field experiments revealed that growth of daphnids was often strongly related to diatom and/or cryptophyte biomass, which was interpreted as an effect of increased EPA supply (Müller-Navarra, 1995a; MüllerNavarra \& Lampert, 1996). Laboratory experiments showed that diatoms and cryptophytes are of high food quality for daphnids (Lundstedt \& Brett, 1991; MüllerNavarra, 1995b; Brett, Müller-Navarra \& Park, 2000) owing to their high EPA concentration. Furthermore, not only algae but also protozoa (heterotrophic nanoflagellates, ciliates) can synthesise EPA de novo (Zhukova \& Kharlamenko, 1999; Martin-Creuzburg, Bec \& von Elert,
2005) and consequently are of good food quality for consumers (Desvilettes \& Bec, 2009).

The fatty acid composition and concentration in plankton organisms is not constant but can be strongly influenced by abiotic factors (Sperfeld \& Wacker, 2011). Low temperatures and low light intensities increase the EPA concentration of diatoms (Thompson, Harrison \& Whyte, 1990; Gladyshev et al., 2010; Piepho, Arts \& Wacker, 2012). Ciliates are able to adjust their polyunsaturated fatty acid (PUFA) composition in response to temperature changes (Nozawa \& Thompson, 1979). Furthermore, low phosphorus availability was found to decrease EPA concentrations in diatoms (Müller-Navarra, 1995b; Piepho et al., 2012).

Polyunsaturated fatty acids can be used as biomarkers for phytoplankton; that is, certain fatty acids indicate the presence of certain phytoplankton groups (Sushchik et al., 2004; Taipale et al., 2009; Gladyshev et al., 2010). EPA is particularly regarded as a biomarker for diatoms and cryptophytes because of their high concentration of this PUFA (Ahlgren et al., 1990; Bec et al., 2003; Müller-Navarra et al., 2004). Fewer studies have also considered protozoans such as ciliates as important EPA sources in the seston (Reuss \& Poulsen, 2002; Bec et al., 2010). In biomarker studies, the PUFA concentration of seston is correlated with plankton biomass and taxonomic composition with the aim of predicting seston taxonomic composition from fatty acid measurements, but owing to the low specificity of most fatty acids, a precise characterisation of the plankton community seems not to be possible (Reuss \& Poulsen, 2002). Here, we test whether a reversed approach is possible, whereby the biomass of specific plankton groups might be used to estimate EPA concentration in the seston, which indicates the food quality for consumers. Additionally, we included temperature and light measurements to account for the effect of these abiotic variables on the EPA concentration of plankton organisms. During the last decade, measurements of sestonic fatty acid concentrations became more common with increasing recognition of their relevance in aquatic food webs. However, still only few fatty acid measurements are available, whereas long-term data sets on plankton taxonomic composition and biomasses exist for many 
well-studied lakes (Anneville, Gammeter \& Straile, 2005; Dokulil \& Teubner, 2005; Jeppesen et al., 2005). The ability to estimate the EPA concentration of lake seston may provide insights into constraints on consumer fitness for years for which no direct fatty acid data are available.

The aim of this study was to develop a model that estimates EPA concentrations in lake seston from plankton biomass, particulate phosphorus concentration, temperature and light intensity. Using multiple linear regression, we fitted data from Lake Constance for these variables to EPA measurements of seston from 2008 to 2009. To determine the accuracy of this approach, we validated the resulting models with EPA measurements from another year in which plankton biomass, temperature and light data were available.

\section{Methods}

\section{Study site and sampling}

Lake Constance $\left(47^{\circ} 40^{\prime} \mathrm{N}, 9^{\circ} 20^{\prime} \mathrm{E}\right)$ is a large, deep, warmmonomictic lake (surface area: $473 \mathrm{~km}^{2}, z_{\text {mean }}=101 \mathrm{~m}$, $z_{\max }=254 \mathrm{~m}$ ) north of the European Alps. After strong eutrophication between 1960 and 1980, when the total phosphorus concentration during the spring circulation increased from $<10$ to $87 \mu \mathrm{g} \mathrm{L}^{-1}$, the lake underwent intensive re-oligotrophication and now approaches its natural oligotrophic state. During spring circulation in 1997, the total phosphorus concentration was $18 \mu \mathrm{g} \mathrm{L}^{-1}$ and further decreased to $<8 \mu \mathrm{g} \mathrm{L}^{-1}$ in 2008 (Internationale Gewässerschutzkommission für den Bodensee, 2008).

Sampling was carried out weekly during the growing season and biweekly during winter in 1997 and from 2008 to 2009 at a long-term sampling site situated in the deep north-western arm of Lake Constance (Überlinger see, $z_{\max }=147 \mathrm{~m}$ ). Water samples were integrated over the depth intervals 0-8 and 8-20 m, which represents approximately the euphotic zone of Lake Constance. Phytoplankton and ciliates were enumerated by the Utermöhl technique. Individual cell sizes were established by measuring average cell volumes of individual taxa and conversions into units of carbon $\left(\mu \mathrm{g} \mathrm{C} \mathrm{L}^{-1}\right)$ using measurements from Lake Constance or from the literature (for details, see Gaedke, 1992). Phytoplankton and ciliate species with a mean length of $<30 \mu \mathrm{m}$ were considered as edible for daphnids (Burns, 1968).

Average light availability in the water layers $0-8,8-20$ and 0-20 m was calculated from measurements of incoming radiation (data from the German National Meteorological Service, Deutscher Wetterdienst, for station Konstanz) and chlorophyll a profiles by assuming a background light attenuation of $0.27 \mathrm{~m}^{-1}$ and a chlorophyll a-specific light attenuation coefficient of $0.021 \mathrm{~m}^{2} \mathrm{mg}^{-1}$ chlorophyll (Peeters et al., 2007).

Temperature profiles were measured using a RBR CTD sonde, and average temperatures for the water layers $0-8$, 8-20 and 0-20 m were calculated.

During the growing season in 1997 (April-October, $6 \mathrm{~m}$ depth; details in Wacker \& Von Elert, 2001) and from April 2008 to April 2009 (routine sampling, 0-8 and 8-20 m depth), seston samples were taken for the analysis of carbon, phosphorus and fatty acids. For the determination of particulate organic carbon (POC), seston $(<30 \mu \mathrm{m})$ was filtered onto pre-combusted glass fibre filters (Whatman GF/F, 25 mm diameter) and analysed using an NCS-2500 analyzer (ThermoQuest $\mathrm{GmbH}$, Egelsbach, Germany). For the determination of particulate phosphorus, lake water was filtered onto acid-rinsed polysulphone filters (HT-200; Pall, Ann Arbor, MI, U.S.A.) and afterwards digested with a solution of $10 \%$ potassium peroxodisulfate and $1.5 \%$ sodium hydroxide for $60 \mathrm{~min}$ at $121{ }^{\circ} \mathrm{C}$. Measurements were taken spectrophotometrically using the molybdateascorbic acid method (Greenberg, Trussel \& Clesceri, 1985). For the analysis of fatty acids, water was filtrated through gauze with a mesh size of $30 \mu \mathrm{m}$ and subsequently onto pre-combusted glass fibre filters (Whatman GF/F, $47 \mathrm{~mm}$ diameter), with about $0.5 \mathrm{mg}$ POC per filter. Lipids were extracted, transesterified into fatty acid methyl esters (FAME), identified and quantified by gas chromatography (6890N Network GC System; Agilent Technologies, Böblingen, Germany) according to Wacker $\&$ Weithoff (2009) with the following configuration: $1 \mu \mathrm{L}$ of the sample was injected in split mode (5:1), vaporised in the injector at $250{ }^{\circ} \mathrm{C}$ and mixed with the carrier gas (helium). FAME were separated by a polysiloxane column (J\&W DB-225, $30 \mathrm{~m} \times 0.25 \mathrm{~mm} \times 0.25 \mu \mathrm{m}$; Agilent Technologies) and a temperature gradient $\left(60^{\circ} \mathrm{C}\right.$ for $1 \mathrm{~min}$, increasing $20^{\circ} \mathrm{C} \mathrm{m^{-1 }}$ until $150{ }^{\circ} \mathrm{C}, 10^{\circ} \mathrm{C} \min ^{-1}$ until $220^{\circ} \mathrm{C}$, for $13.75 \mathrm{~min}$ ). FAME were detected by a flame ionisation detector (FID) at $250^{\circ} \mathrm{C}$ and quantified by comparison with internal standards and by using multipoint standard calibration curves determined for each FAME, from mixtures of known composition. FAME were identified via known retention times of reference substances (47885-U, Supelco 37 component FAME mix; Sigma-Aldrich, Steinheim, Germany).

\section{Statistics - model calculation and model selection}

The biomass of ciliates, diatoms and cryptophytes, EPA concentration and light data were log-transformed and 
met the assumption of homogeneity of variance and normally distributed errors.

As diatoms, cryptophytes and ciliates are evidently rich in EPA (Ahlgren et al., 1990; Bec et al., 2010), these taxa were used as separate predictors. Other phytoplankton groups such as chrysophytes, dinophytes, cyanobacteria and chlorophytes were pooled into one variable ('other') because they contributed only little to the total plankton biomass (Fig. 1), or contain no or only low amounts of EPA (Ahlgren et al., 1992). In a first approach, we used multiple linear regression to fit the depth-resolved plankton biomass data to measured EPA concentrations in an additive model. The two depth intervals were sampled at 35 dates in 2008/2009, and during winter, only one integrated depth was sampled $(0-20 \mathrm{~m})$, providing a total of 77 data points.

We then introduced the variables mean temperature, mean light intensity and mean molar phosphorus/carbon $(\mathrm{P}: \mathrm{C}$, mol:mol) ratio $(0-20 \mathrm{~m})$ and depth as factor $(0$ $8 \mathrm{~m}=$ factor level $1 ; 8-20 \mathrm{~m}=$ factor level 2) into the model. Mean values of abiotic variables and $\mathrm{P}: \mathrm{C}$ ratio

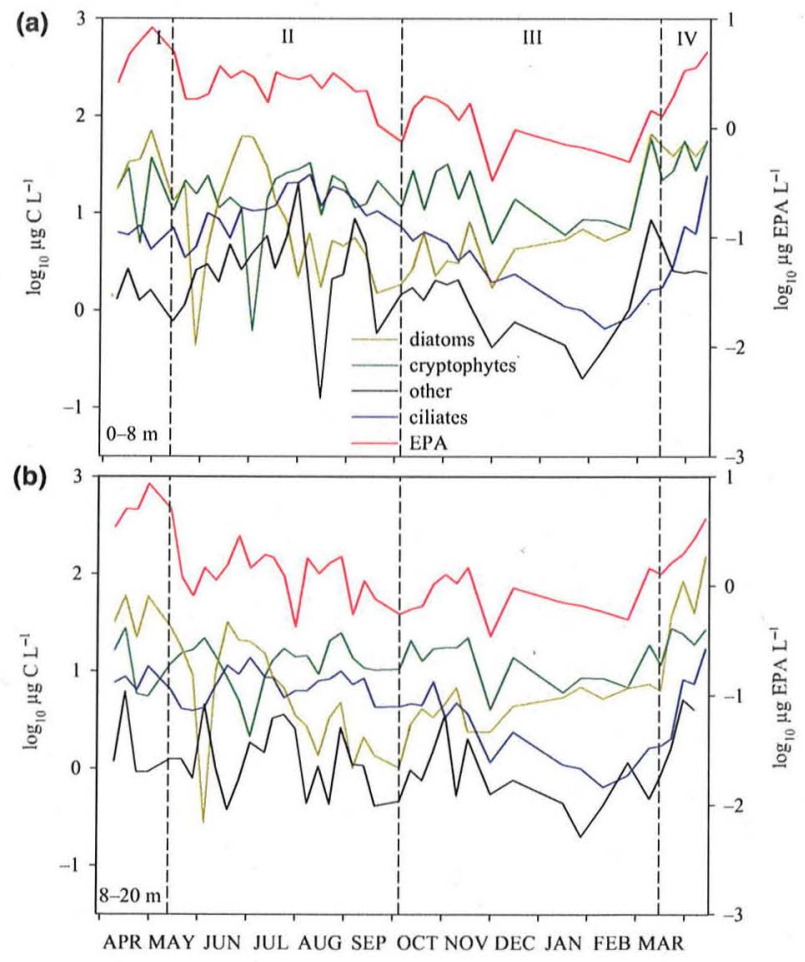

Fig. 1 Course of plankton biomasses and measured EPA concentration in Lake Constance in 2008/2009 in 0-8 m (a) and 8-20 m (b) depth. The sampling period is divided into the phases spring (I, IV) clear water phase and summer (II), and autumn and winter (III). The phytoplankton taxa cyanobacteria, chlorophytes, chrysophytes and dinophytes were pooled because of low abundances and are depicted as 'other' phytoplankton.
$(0-20 \mathrm{~m})$ were used to test for large-scale seasonal effects between summer (high mean values) and winter conditions (low mean values). Mean temperature and mean light intensity were uncorrelated during the study period (cf. Fig. 2), suggesting that these variables do not account for the same seasonal effects. The variable depth was introduced to test for possible depth-related effects on EPA concentrations (e.g. lower light and temperature in 8-20 $\mathrm{m}$ than in 0-8 $\mathrm{m}$ depth). Winter values (Decemberearly March) were excluded in this particular as during these seven samplings, only one integrated depth $(0$ $20 \mathrm{~m}$ ) was available, hence 70 data points were used. The variable mean $\mathrm{P}: \mathrm{C}$ ratio was subsequently excluded from further analysis owing to its low relative importance. In order to test whether the effects of depth on EPA concentrations were attributable to lower temperature or reduced light availability, we replaced the variable depth in a third approach with the variables deviation from mean temperature in the two depth intervals (0-8 and 8-20 m) and deviation from mean light intensity in the two depths and their interactions with the biomass predictors and the abiotic factors. To test for a possible depth-related influence of the abiotic variables on EPA concentrations, we used the deviation from the mean values in both depths (0-8 and 8-20 m). We chose this approach because it represents more distinctly the differences between the depths and accounts for small-scale dynamics (interweek variability), whereas for the absolute light and temperature values in the distinct depth intervals, the effects of depth and season are entwined. Winter values $(0-20 \mathrm{~m})$ of all variables were included in this approach resulting in 77 data points.

Model selection with the Akaike Information Criterion corrected for small sample sizes (AICc) was used to determine the model that best predicts the measured EPA concentrations in the three approaches (statistic software $\mathrm{R}$, version 2.13.0; GLMULTI package, $\mathrm{R}$ Development Core Team, http://www.r-project.org). The full models (see Tables 1, 2 and 3) were stepwise-simplified by removing one or more variables, and AICc and Akaike weights for each model were computed. AICc was used to select the best models, while Akaike weights can be interpreted as the probability in favour of each model relative to the other models considered. To assess the relative importance of the different predictors, the sum of Akaike weights was computed over a subset of models that included this variable (Burnham \& Anderson, 1998; Johnson \& Omland, 2004). Significant interaction terms in the third approach were analysed graphically for their effect on EPA concentrations. For that, EPA concentrations were estimated with the model with the lowest AICC 

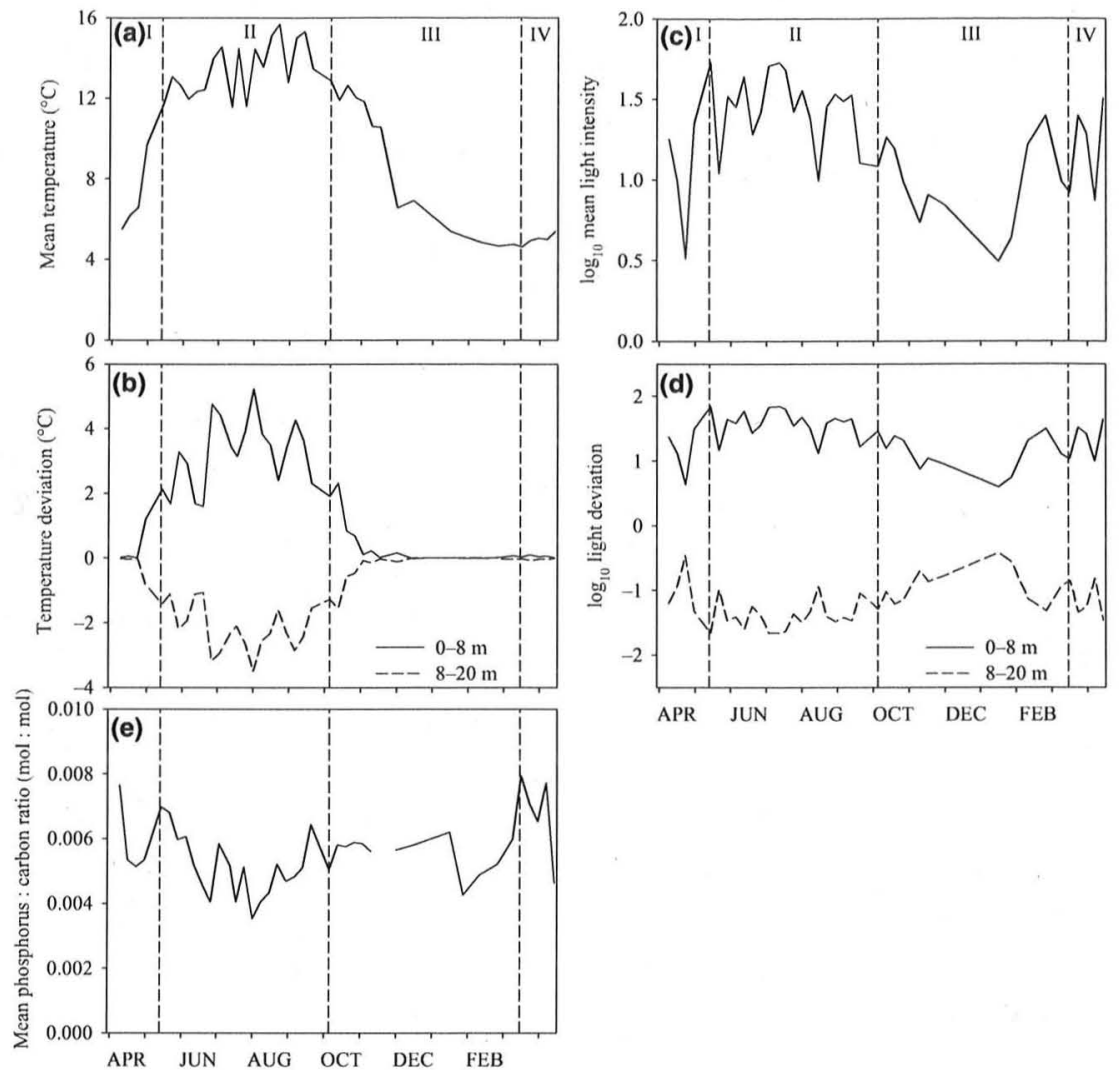

Fig. 2 Course of mean temperature $\left({ }^{\circ} \mathrm{C}\right.$ ) integrated over 0-20 $\mathrm{m}$ in 2008/2009 (a) and of the temperature deviations from the mean temperature in 0-8 and 8-20 m depth (b). Course of mean light intensity $\left[\log _{10}\left(\mathrm{~W} \mathrm{~m}^{-2}\right.\right.$ day $\left.\left.^{-1}\right)\right]$ integrated over $0-20 \mathrm{~m}$ (c) and of the deviations from the mean light intensity in 0-8 and 8-20 m depth (d). Course of the mean phosphorus/carbon ratio (mol:mol) integrated over 0-20 m depth (e). The sampling period is divided into the phases spring (I, IV), clear water phase and summer (II), and autumn and winter (III).

Table 1 Results of the first model approach including the variables ciliates (cil), diatoms (dia), cryptophytes (cry) and other phytoplankton groups (other). The two depth intervals were sampled on 35 dates in 2008/2009 (during winter only one integrated depth was sampled, from 0 to $20 \mathrm{~m}$ ), providing a total of 77 data points. For each model, adjusted $R^{2}$ (adj. $R^{2}$ ), corrected Akaike Information Criterion (AICc), the difference between the AICc of each model and the minimum AICc ( $\mathrm{AICC}$ ) and Akaike weights (AICw) are given. The 10 best models according to AICc, and the single predictor models are shown. Following the rule of thumb that models with AICc $<2$ apart are assumed to be equal, the four models with lowest AICc are highlighted with bold

\begin{tabular}{|c|c|c|c|c|c|c|c|c|}
\hline \multirow[b]{2}{*}{ best } & \multicolumn{4}{|c|}{ Variables included } & \multirow{2}{*}{$\frac{\operatorname{adj} . R^{2}}{0.61}$} & \multirow{2}{*}{$\begin{array}{l}\text { AICc } \\
-\mathbf{9 . 4 1}\end{array}$} & \multirow{2}{*}{$\frac{\triangle \mathrm{AICC}}{\mathbf{0 . 0 0}}$} & \multirow{2}{*}{$\frac{\mathrm{AICW}}{0.29}$} \\
\hline & $\mathrm{cil}^{* * *}$ & $\operatorname{dia}^{* * *}$ & & other $^{+}$ & & & & \\
\hline & $\mathrm{cil}^{* * *}$ & $\mathrm{dia}^{* * *}$ & $\operatorname{cry}^{+}$ & & 0.61 & -9.38 & 0.03 & 0.28 \\
\hline & $\operatorname{cil}^{* * *}$ & $\operatorname{dia}^{* * *}$ & cry & other & 0.62 & -8.97 & 0.44 & 0.23 \\
\hline & $\mathrm{cil}^{* * *}$ & $\operatorname{dia}^{* * *}$ & & & 0.60 & -8.63 & 0.78 & 0.20 \\
\hline & & $\operatorname{dia}^{* * *}$ & & other** & 0.41 & 21.45 & 30.86 & 0.00 \\
\hline & & $\operatorname{dia}{ }^{* * *}$ & cry & other* & 0.41 & 21.97 & 31.38 & 0.00 \\
\hline & & $\mathrm{dia}^{* * *}$ & cry $^{+}$ & & 0.37 & 26.44 & 35.85 & 0.00 \\
\hline & $\operatorname{cil}^{* * *}$ & & & other $^{\dagger}$ & 0.36 & 27.68 & 37.09 & 0.00 \\
\hline & & $\operatorname{dia}{ }^{* * *}$ & & & 0.34 & 28.22 & 37.63 & 0.00 \\
\hline & $\mathrm{cil}^{* * *}$ & & cry & & 0.35 & 28.43 & 37.85 & 0.00 \\
\hline \multirow{3}{*}{ single } & $\operatorname{cil}^{* * *}$ & & & & 0.34 & 28.86 & 38.27 & 0.00 \\
\hline & & & & other** & 0.11 & 51.24 & 60.65 & 0.00 \\
\hline & & & $\operatorname{cry}^{\dagger}$ & & 0.04 & 56.79 & 66.20 & 0.00 \\
\hline
\end{tabular}

${ }^{\dagger} P<0.1 ;{ }^{*} P<0.05 ;{ }^{* *} P<0.01 ;{ }^{* *} P<0.001$. 
Table 2 Results of the second model approach including the variables ciliates (cil), diatoms (dia), cryptophytes (cry), other phytoplankton (other), mean light intensity $\left(L_{m}\right)$, mean temperature $\left(T_{m}\right)$, mean phosphorus/carbon ratio $\left(P_{m}\right)$ and depth. For the two depth intervals, 35 dates with measurements were used (total $N=70$ ). For each model, adjusted $R^{2}$ (adj. $R^{2}$ ), corrected Akaike Information Criterion (AICc), the difference between the AICc of each model and the minimum AICc ( $\triangle \mathrm{AICC}$ ) and Akaike weights (AICw) are given. The ten best models according to AICc, and the single predictor models are shown. Following the rule of thumb that models with AICc $<2$ apart are assumed to be equal, the five models with lowest AICc are highlighted in bold. A minus sign indicates a negative impact of a variable

\begin{tabular}{|c|c|c|c|c|c|c|c|c|c|c|c|c|}
\hline \multirow[b]{2}{*}{ best } & \multicolumn{8}{|c|}{ Variables included } & \multirow{2}{*}{$\frac{\text { adj. } \mathrm{R}^{2}}{0.60}$} & \multirow{2}{*}{$\begin{array}{l}\mathrm{AICc} \\
-7.57\end{array}$} & \multirow{2}{*}{$\frac{\Delta \mathrm{AIC}}{0.00}$} & \multirow{2}{*}{$\frac{\mathrm{AICw}}{0.20}$} \\
\hline & cil $^{* * *}$ & $\operatorname{dia}^{* * *}$ & & & & $-T_{m}$ & - depth ${ }^{* *}$ & & & & & \\
\hline & $\mathrm{cil}^{* * * *}$ & $\operatorname{dia}^{* * *}$ & & other $^{\dagger}$ & $-L_{\mathrm{m}}{ }^{*}$ & & - depth $^{+}$ & & 0.62 & -6.78 & 0.79 & 0.13 \\
\hline & $\mathrm{cil}^{* * *}$ & $\mathrm{dia}^{* * *}$ & & & $-L_{m}^{\dagger}$ & & - depth** & & 0.61 & -6.14 & 1.43 & 0.10 \\
\hline & $\operatorname{cil}^{* * *}$ & $\mathrm{dia}^{* * *}$ & cry & & & $-T_{m}$ & - depth** & & 0.60 & -5.90 & 1.67 & 0.09 \\
\hline & $\mathrm{cil}^{* * *}$ & $\mathrm{dia}^{* * *}$ & cry & other & & & -depth* & & 0.60 & -5.79 & 1.77 & 0.08 \\
\hline & $\mathrm{cil}^{* * *}$ & $\mathrm{dia}^{* * *}$ & & other** & $-L_{\mathrm{m}}^{*}$ & & & & 0.60 & -5.35 & 2.21 & 0.06 \\
\hline & $\mathrm{cil}^{* * *}$ & $\operatorname{dia}^{* * *}$ & cry & other & & $-T_{\mathrm{m}}$ & -depth* & . & 0.60 & -4.84 & 2.72 & 0.05 \\
\hline & $\mathrm{cil}^{* * * *}$ & $\operatorname{dia}^{* * *}$ & cry & other* & $-L_{\mathrm{m}}^{*}$ & & & & 0.61 & -4.67 & 2.90 & 0.05 \\
\hline & $\mathrm{cil}^{* * * *}$ & $\operatorname{dia}^{* * *}$ & & & $-L_{\mathrm{m}}$ & $-T_{\mathrm{m}}$ & - depth$^{* *}$ & & 0.61 & -4.55 & 3.02 & 0.04 \\
\hline & $\mathrm{cil}^{* * *}$ & $\operatorname{dia}^{* * *}$ & & other* & & $-T_{\mathrm{m}}{ }^{\dagger}$ & & & 0.58 & -3.76 & 3.81 & 0.03 \\
\hline \multirow{9}{*}{$\begin{array}{l}\text { full } \\
\text { single }\end{array}$} & $\mathrm{cil}^{* * * *}$ & $\operatorname{dia}^{* * *}$ & cry & other & $-L_{\mathrm{m}}$ & $-T_{\mathrm{m}}$ & - depth $^{\dagger}$ & $-P_{m}$ & 0.61 & 1.84 & 9.40 & 0.00 \\
\hline & & $\operatorname{dia}^{* * *}$ & & & & & & & 0.41 & 16.05 & 23.61 & 0.00 \\
\hline & $\mathrm{cil}^{* * *}$ & & & & & & & & 0.25 & 31.77 & 39.34 & 0.00 \\
\hline & & & & & & & - depth$^{* *}$ & & 0.10 & 43.91 & 51.48 & 0.00 \\
\hline & & & & other* & & & & & 0.08 & 45.97 & 53.54 & 0.00 \\
\hline & & & & & & $-T_{\mathrm{m}}$ & & & 0.07 & 46.61 & 54.17 & 0.00 \\
\hline & & & cry & & & & & & 0.02 & 50.31 & 57.87 & 0.00 \\
\hline & & & & & $L_{\mathrm{m}}$ & & & & -0.01 & 52.38 & 59.95 & 0.00 \\
\hline & & & & & & & & $-P_{m}$ & -0.01 & 52.85 & 60.42 & 0.00 \\
\hline
\end{tabular}

${ }^{+} P<0.1 ;{ }^{*} P<0.05 ;{ }^{* * P}<0.01 ; * * * P<0.001$.

for different levels of the variables, covering the data range of the study period (effects package).

To check for collinearity between the eight predictors (biomass of ciliates, diatoms, cryptophytes, 'other' phytoplankton, mean light intensity, light deviation, mean temperature and temperature deviation), the Variance Inflation Factors were computed for these variables (car package). The Variance Inflation Factors were all below 10; hence, no collinearity was apparent.

The best model of the first and second approaches, respectively, was used to predict the EPA concentrations of seston in 1997, which then were correlated with the values measured in 1997 to determine the validity of the best models.

\section{Results}

\section{Plankton biomass and abiotic conditions}

From April 2008 to April 2009, the EPA concentration in seston $<30 \mu \mathrm{m}$ in $0-8 \mathrm{~m}$ depth had a maximum of $8.2 \mu \mathrm{g} \mathrm{L}^{-1}$ in spring 2008 (Fig. 1a), which coincided with the highest biomass of diatom biomass $\left(72 \mu \mathrm{g} \mathrm{C} \mathrm{L}{ }^{-1}\right)$. Maximum cryptophyte biomass was found during spring $2009\left(60 \mu \mathrm{g} \mathrm{C} \mathrm{L}^{-1}\right)$, and ciliates had a maximum of $25 \mu \mathrm{g} \mathrm{C} \mathrm{L}^{-1}$ in summer 2008. The sum of chlorophytes, cyanobacteria, chrysophytes and dinophytes ('other') was quantitatively of minor importance compared to the other plankton groups, with their biomass mostly below $10 \mu \mathrm{g} \mathrm{C} \mathrm{L}{ }^{-1}$.

In 8-20 $\mathrm{m}$ depth, EPA concentrations were lowest in November $2008\left(0.2 \mu \mathrm{g} \mathrm{L}^{-1}\right.$; Fig. $\left.1 \mathrm{~b}\right)$ and reached a maximum in spring $2008\left(8.5 \mu \mathrm{g} \mathrm{L}^{-1}\right)$, whereas the highest diatom biomass was measured in spring 2009 $\left(154 \mu \mathrm{g} \mathrm{C} \mathrm{L}^{-1}\right)$. Cryptophyte and ciliate biomass were lower in the deeper than in the upper water layer with maxima of 28 and $17 \mu \mathrm{g} \mathrm{C} \mathrm{L}^{-1}$, respectively. 'Other' phytoplankton was again the group with the lowest biomass in this depth with a maximum of $6.2 \mu \mathrm{g} \mathrm{C} \mathrm{L}^{-1}$.

Mean phosphorus/carbon (mol:mol) ratio varied between 0.003 and 0.008 with the lowest values during summer 2008 (Fig. 2e). Mean temperature $(0-20 \mathrm{~m}$ ) varied between $\angle 5{ }^{\circ} \mathrm{C}$ during winter and spring and $19.7^{\circ} \mathrm{C}$ during summer 2008 (Fig. 2a). Temperature deviations from the mean temperature in $0-8$ and $8-20 \mathrm{~m}$ were $<1{ }^{\circ} \mathrm{C}$ during winter and spring (Fig. $2 \mathrm{~b}$ ) and highest in late July $\left(0-8 \mathrm{~m}: 5.2{ }^{\circ} \mathrm{C}, 8-20 \mathrm{~m}:-3.5^{\circ} \mathrm{C}\right)$. The mean daily light intensity varied between $3.1 \mathrm{~W} \mathrm{~m}^{-2}$ day $^{-1}$ in January 2009 and $53.5 \mathrm{~W} \mathrm{~m}^{-2}$ day $^{-1}$ in May 2008 (Fig. 2c). The deviation of the light intensity from the mean light intensity in 0-8 $\mathrm{m}$ varied between 3.9 and $69 \mathrm{~W} \mathrm{~m}^{-2}$ day $^{-1}$ during the 
Table 3 Results of the third model approach including all variables [ciliates (cil), diatoms (dia), cryptophytes (cry), mean light intensity $\left(L_{\mathrm{m}}\right)$, mean temperature $\left(T_{\mathrm{m}}\right)$ and deviations of light $\left(L_{d}\right)$ and temperature $\left(T_{d}\right)$ from the mean values] and interaction terms (depicted by colons between variables). The two depth intervals were sampled on 35 dates in $2008 / 2009$ (during winter only one integrated depth was sampled, from 0 to $20 \mathrm{~m}$ ), providing a total of 77 data points. For each model, adjusted $R^{2}$ (adj. $R^{2}$ ), corrected Akaike Information Criterion (AICc), the difference between the AICc of each model and the minimum AICc ( $\triangle \mathrm{AICc}$ ) and Akaike weights (AICw) are given. The ten best models according to AICc (best), the full model (full) and the single predictor models (single) are shown. In the full model, the interactions between variables cry: $L_{\mathrm{d}}$, dia: $T_{\mathrm{d}}$, cry: $T_{\mathrm{d}}$, cil: $T_{\mathrm{m}}$, dia: $T_{\mathrm{m}}$ and cry: $T_{\mathrm{m}}$ and all interactions between 'other' and the abiotic variables were not significant and are not shown here. Following the rule of thumb that models with AICc $<2$ apart are assumed to be equal, the four models with lowest AICc are highlighted in bold. A minus sign indicates a negative impact of a variable

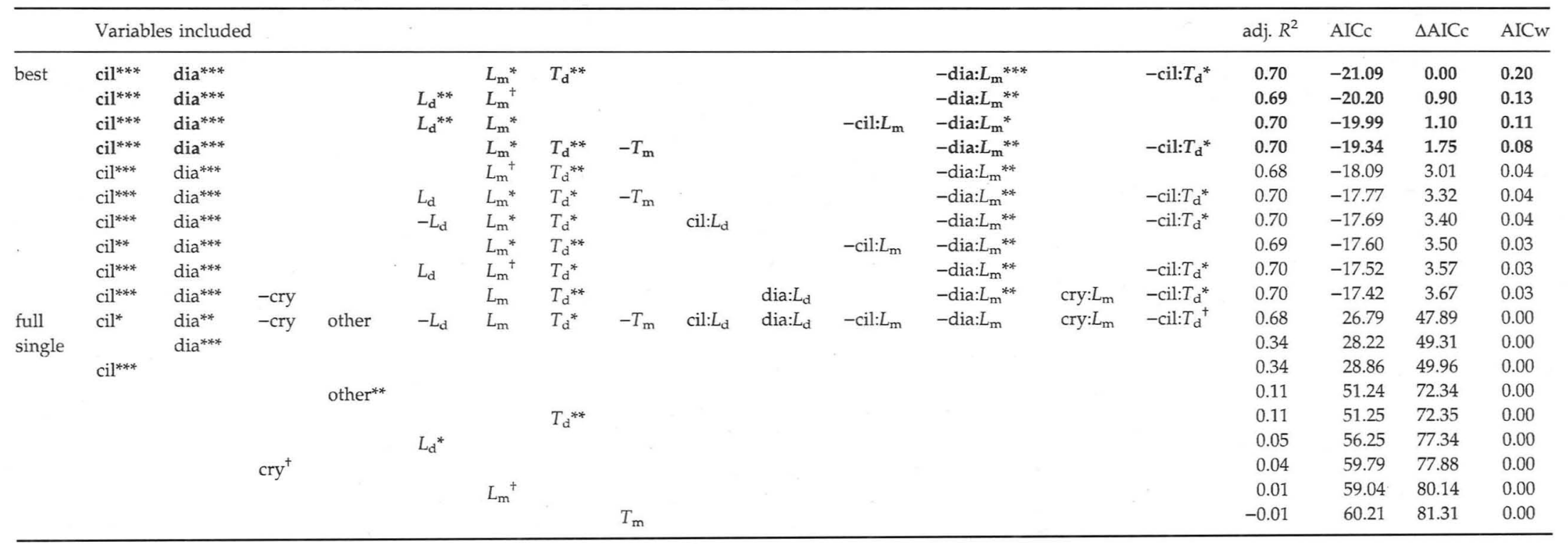

${ }^{+} P<0.1 ; * P<0.05 ; * * P<0.01 ; * * P<0.001$. 
study period (Fig. 2d). In 8-20 m, the deviation ranged from -2.6 to $-46 \mathrm{~W} \mathrm{~m}^{-2}$ day $^{-1}$.

\section{Model selection}

The first approach including only different plankton groups as independent variables resulted in four best models according to AICc (Table 1; for individual parameter values, see Table S1). As a rule of thumb, models with AICc differences $<2$ are assumed to fit equally well (Bolker, 2008). In these four models, the EPA-rich ciliates and diatoms were always included and the high sums of Akaike weights of these variables confirm their high predictive power for EPA concentrations (Fig. 3). Cryptophytes and 'other' phytoplankton were additionally included in two of the four models with the lowest AICC, respectively, and their inclusion increased model $R^{2}$ slightly (Table 1). The model that included all biotic variables explained most variability (adjusted $R^{2}=0.62$ ), and it closely reflected the interweek dynamics of EPA concentrations during summer 2008 and spring 2009, but underestimated the spring EPA concentrations in 2008 (Fig. 4).

In a second approach, the variables mean temperature, light and P:C ratio and depth were included in the

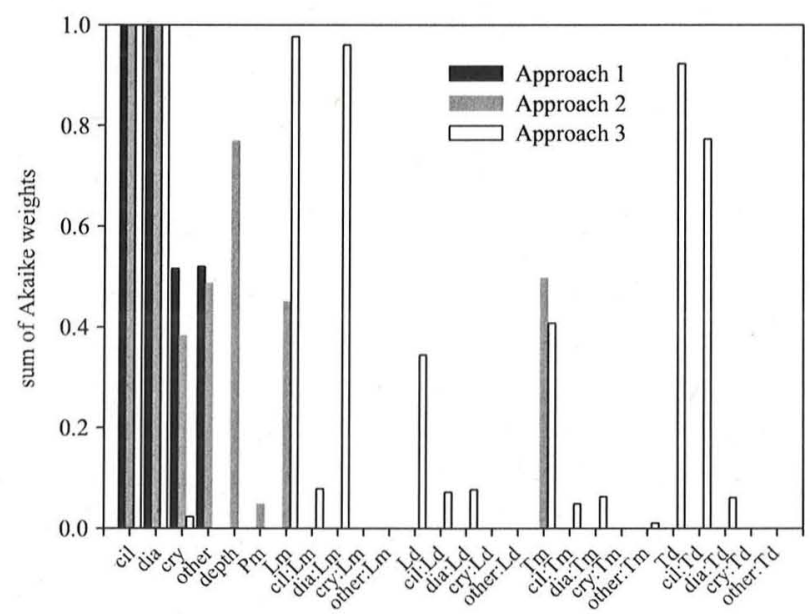

Fig. 3 Relative importance of the variables biomass of ciliates (cil), diatoms (dia), cryptophytes (cry) and other phytoplankton (other) in the pure biomass approach (approach 1, black bars) calculated from the sum of Akaike weights of all models in which they were included. Grey bars show the relative importance of all variables included in the second approach [approach $2 ; L_{\mathrm{m}}$, mean light intensity; $T_{\mathrm{m}}$ mean temperature; $\mathrm{P}_{\mathrm{m}}$, mean phosphorus/carbon ratio $(\mathrm{mol}: \mathrm{mol})]$. White bars show the relative importance of all variables and interaction terms (depicted by a colon, e.g. cil: $L_{\mathrm{m}}$ ) that were included in the third approach (approach $3 ; L_{\mathrm{d}}$, light deviation; $T_{\mathrm{d}}$, temperature deviation). model. The five best models according to AICc (Table 2) did not include the predictor mean particulate phosphorus concentration, while the variables mean $(0-20 \mathrm{~m})$ temperature and light intensity and depth, all with a negative impact on EPA concentration, were included. Adjusted $\mathrm{R}^{2}$ and AICc values of the models in this approach are not directly comparable with the values from the first approach, because winter values were not included in model selection in this second approach. The model with the lowest AICc (adjusted $R^{2}=0.60$ ) closely reflected the interweek dynamics of EPA concentrations during summer 2008 and spring 2009, but underestimated the spring EPA concentrations in 2008 (Fig. 4). The pure biomass model of the second approach explained $57 \%$ of the variability of EPA concentrations (AICC $=-2.79$ ),

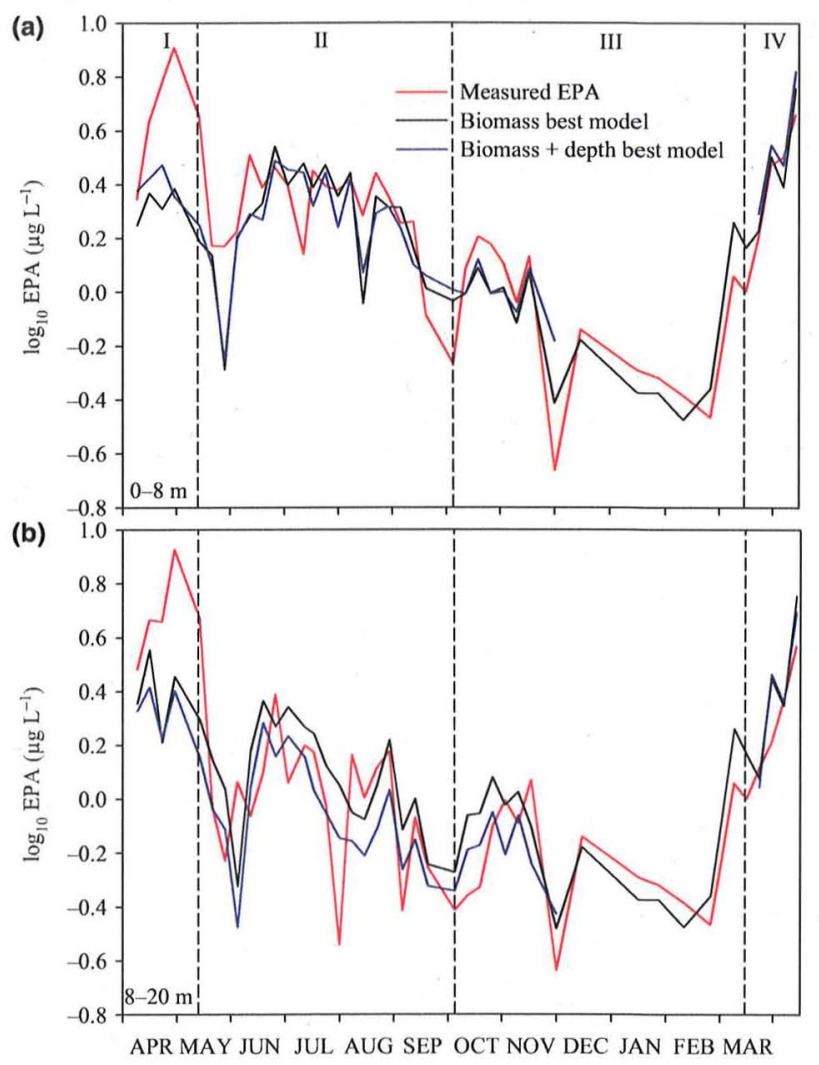

Fig. 4 Course of measured and estimated EPA $\left(\log \mu \mathrm{g} \mathrm{L}^{-1}\right)$ with the best models of the first and second approaches, respectively Ipurely biomass (Table 1), and biomass plus depth and abiotic variables (Table 2)] in 0-8 $\mathrm{m}$ (a) and 8-20 $\mathrm{m}$ (b) in 2008/2009. For the first approach, seven data points from the winter in which only one depth $(0-20 \mathrm{~m})$ was sampled were included in the analyses. By using depth as an additional factor in the analysis, these dates had to be excluded from the analysis. The sampling period is divided into the phases spring (I, IV), clear water phase and summer (II), and autumn and winter (III). 
which shows that the inclusion of mean temperature or light and depth improved the model performance.

To further investigate potential mechanisms giving rise to the depth effect on EPA concentrations, we additionally introduced the variables deviation from mean temperature in the two depth intervals $(0-8$ and $8-20 \mathrm{~m})$ and deviation from mean light intensity in the two depths. In this third approach, four models were the best according to AICc (Table 3; for individual parameter values, see Table S3), and the models explained $69-70 \%$ of the variability of the data. The predictors cryptophyte and 'other' phytoplankton biomass and their interactions with temperature and light were not included in these models. Their small sums of Akaike weights confirm their low relevance as predictors of EPA concentration in this approach (Fig. 3). The most important predictors that were included in the best models were ciliates and diatoms. In addition, all considered abiotic variables, as well as the negative interaction terms between diatoms and mean light and between ciliates and temperature deviation, were present in the best models (Table 3). Compared to the first approach, the best biomass model (containing the variables ciliates, diatoms, cryptophytes and 'other' phytoplankton; Table 1) had a higher AICc $(-8.97)$ and explained less variability (62\%), which shows that the inclusion of the abiotic factors improved the fit of the models. The effect plots for the interaction terms in the model with the lowest AICC display the influence of different abiotic conditions on the EPA concentration of plankton biomass (Fig. 5). The effect of the negative interaction between diatom biomass and mean light intensity is that at a low mean light intensity, an increase in diatom biomass leads to a stronger increase in EPA concentrations than the same biomass increase at high mean light intensity (Fig. 5a). The same applies to the negative interaction between ciliate biomass and temperature deviation, where an increase in ciliate biomass at a negative temperature deviation leads to a stronger increase in EPA concentrations than the same biomass increase at a positive temperature deviation (Fig. 5b).

The estimation of EPA concentrations for 1997 with the best models of the first approach and the second approach, respectively, resulted in significant correlations between measured and estimated EPA concentrations (biomass full model $R^{2}=0.80$; biomass + depth best model $R^{2}=0.87$; Fig. 6).

\section{Discussion}

We show that it is possible to estimate the EPA concentration of lake seston from its taxonomic composition and abiotic factors. We focused on this PUFA because of its relevance in the plankton food web, especially for higher consumers that depend on EPA supply from their food. Furthermore, we analysed the contribution of protozoa to seston fatty acid composition, which has rarely been considered except in the study by Bec et al. (2010) and the present study.

Previous findings suggesting the importance of ciliates, diatoms and cryptophytes as the important EPA providers (Beach et al., 1970; Ahlgren et al., 1990; Zhukova \& Kharlamenko, 1999) were confirmed by their presence in
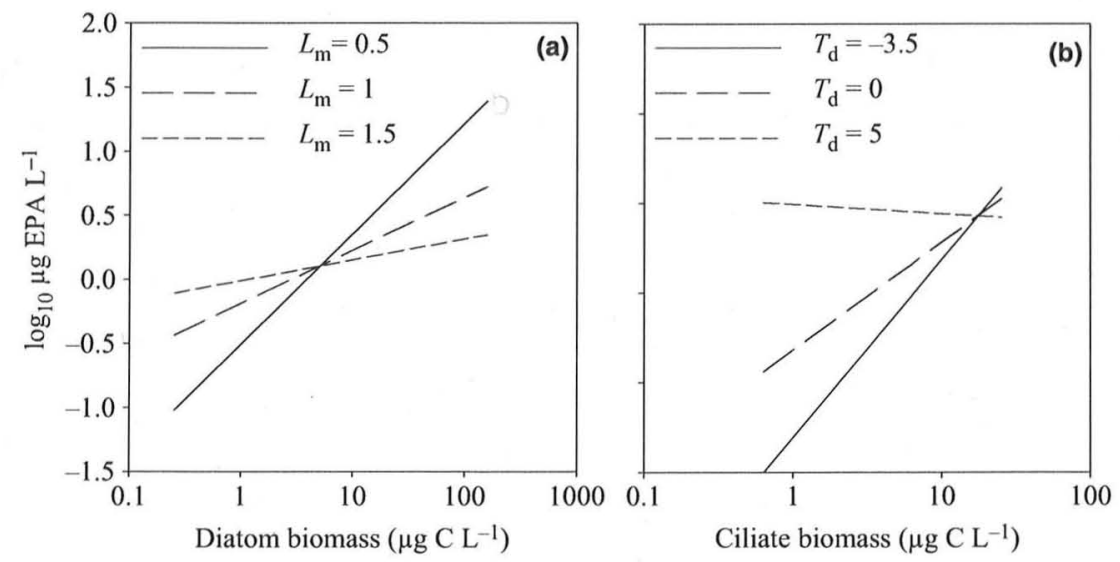

Fig. 5 Effect plots for the interaction terms between diatoms and mean light intensity $\left(L_{\mathrm{m}}\right)$ (a) and between ciliates and temperature deviation $\left(T_{\mathrm{d}}\right)(\mathrm{b})$ for the best model of the third approach (Table 3 ). The estimated EPA concentrations are shown at increasing diatom or ciliate biomass at three levels of mean light intensity $\left[\log _{10}\left(\mathrm{~W} \mathrm{~m}^{-2}\right.\right.$ day $\left.\left.^{-1}\right)\right]$ and temperature deviation $\left({ }^{\circ} \mathrm{C}\right)$, respectively. The data range of the variables was chosen according to the data measured during the study period. EPA concentrations were estimated with the best model that included abiotic variables (Table 3). 


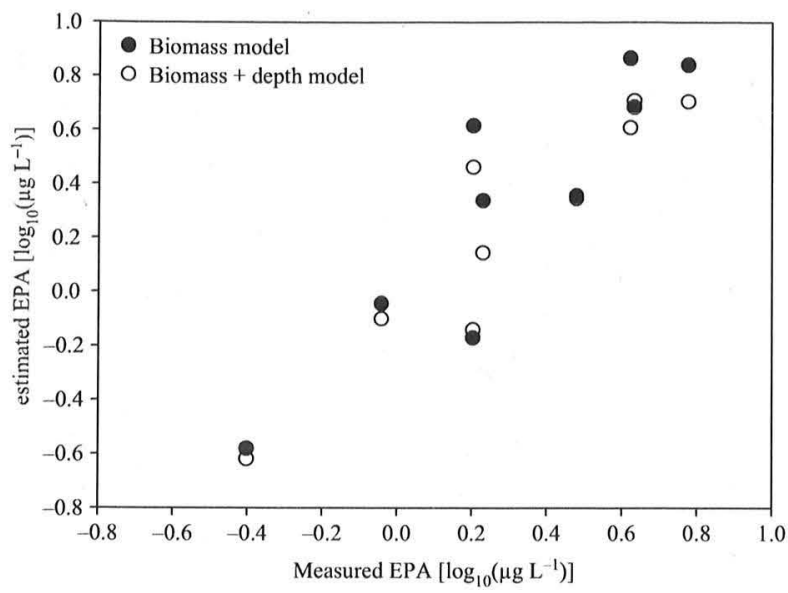

Fig. 6 Correlation between measured EPA concentrations $\left(\log _{10} \mu \mathrm{g} \mathrm{L}^{-1}\right)$ of Lake Constance seston in 1997 and estimated EPA concentrations with the best model including only biomasses ( Table 1) and the best model from the second approach including biomass, depth and mean temperature $(\mathrm{O}$; Table 2).

the best models according to AICc (Table 1) and the relative importance of these predictors (Fig. 3). The predictor 'other' phytoplankton, containing the pooled biomass of cyanobacteria, chlorophytes, chrysophytes and dinophytes, was also included in the set of best models, suggesting that despite their low abundance, chrysophytes and dinophytes may contribute as much as cryptophytes to the EPA availability in the seston. However, the inclusion of the variables cryptophytes and 'other' phytoplankton did not increase adjusted $\mathrm{R}^{2}$ or decrease AICc of the models, which underlines that ciliates and diatoms are the most important predictors for EPA concentrations.

Heterotrophic nanoflagellates (HNF) are known to contain high amounts of EPA (Desvilettes \& Bec, 2009) and would have been a valuable variable in our calculations. Unfortunately, we could not include HNF in our study, because biomass data were only partly available and those available were not depth-resolved. Nevertheless, for Lake Constance seston, we expect only a minor effect on EPA concentration. HNF biomass decreased strongly during re-oligotrophication of Lake Constance (Kamjunke, Straile \& Gaedke, 2009), and accordingly, biomass of HNF in 2008 was very low $\left(0.05-1.7 \mu \mathrm{g} \mathrm{C} \mathrm{L}^{-1}\right)$.

A problem that might arise in other lakes in determining the EPA concentration from biomass can be a higher diversity in one taxa than encountered in Lake Constance. Different species of the same taxa may contain different EPA concentrations (e.g. Viso \& Marty, 1993); hence, if, for example, during part of the season Cyclotella dominates, while in another part Stephanodiscus is the dominant diatom group, as found in a Siberian reservoir (Sushchik et al., 2004), one should consider separating these groups as predictors instead of pooling all diatoms into one variable. This was not necessary in our study, because diatoms were dominated by Cyclotella (62-99.8\% of total diatom biomass) throughout the study period. In one lake, diatoms had very low EPA concentrations and another plankton group (Euglenophyta) was more important as an EPA source (Sushchik et al., 2003); therefore, diatoms may predict EPA concentration in other lakes less well.

We show that the relative importance of ciliates as an EPA source is high in Lake Constance. The best model without this predictor in the first approach explained $41 \%$ of EPA variability, while the best models including ciliates explained up to $62 \%$ of the variability (Table 1 ). Nevertheless, the role of ciliates has often been neglected in studies that correlate seston fatty acid composition and plankton taxonomic composition (e.g. Müller-Navarra \& Lampert, 1996; Sushchik et al., 2004; Kainz et al., 2009), and only few researchers have more recently considered their role as PUFA suppliers (Reuss \& Poulsen, 2002; Bec et al., 2010; Gladyshev et al., 2010). The fatty acid composition of ciliates and hence their nutritional value for consumers seem to be highly variable (DeBiase, Sanders \& Porter, 1990; Desvilettes et al., 1997; Boëchat \& Adrian, 2005; Martin-Creuzburg et al., 2005), probably mainly depending on species, species capability for de novo synthesis, and on their food source (bacteria or phytoplankton). However, their ability not only to repack and accumulate PUFAs from their diet (Harvey, Ederington \& McManus, 1997; Klein Breteler, Koski \& Rampen, 2004; Gladyshev et al., 2010) but also to synthesise PUFAs de novo (Zhukova \& Kharlamenko, 1999; Martin-Creuzburg et al., 2005; Chu et al., 2009) usually leads to a considerable trophic upgrading of the diet of their consumers (Klein Breteler et al., 1999). Field studies and mesocosm experiments suggest that daphnids feed quite efficiently on small ciliates (Marchessault \& Mazumder, 1997; Jürgens, Skibbe \& Jeppesen, 1999; Zöllner et al., 2003), and some studies demonstrated the high food quality of ciliates for daphnids (DeBiase et al., 1990; Wickham, Gilbert \& Berninger, 1993).

The best biomass model according to AICc was sufficient to describe the weekly EPA dynamics during summer, but it underestimated spring concentrations (Fig. 4). The predictability of EPA with the biomass model may be low during spring because the fatty acid composition of plankton organisms can be influenced by temperature and light intensity. Gladyshev et al. (2010) showed that the diatom Cyclotella contains more EPA at low temperature (spring conditions) compared to high 
temperature (summer conditions) (Gladyshev et al., 2010). Likewise, higher EPA concentrations are often found at low light conditions (Thompson et al., 1990). This lowers the predictability of the model that includes biomass but no abiotic variables during spring and which probably led to the underestimation of EPA concentrations during spring 2008 and 2009 with the biomass model (Fig. 4).

The second approach additionally considered the variables mean temperature, light intensity, P : C ratio and depth. It resulted in five best models according to AICC that included the predictors mean temperature, mean light and depth. Both abiotic variables, mean temperature and mean light intensity, had a negative effect on EPA concentrations. It is unlikely that the general seasonal trend described by the predictors is the same, because in the case of Lake Constance mean light and temperature were not correlated. The negative effect of both predictors is in accordance with laboratory studies that showed that at low temperatures and light intensities, the EPA concentration in phytoplankton is usually higher (Thompson et al., 1990; Piepho et al., 2012). The variable mean $\mathrm{P}: \mathrm{C}$ ratio was not a significant predictor, probably because the range of the phosphorus concentration was too low to influence EPA concentration in the organisms. Hence, we found no evidence for an influence of phosphorus on EPA concentrations in seston organisms in Lake Constance, even though laboratory studies have suggested such effects (Müller-Navarra, 1995b; Piepho et al., 2012). Despite the inclusion of mean temperature and light, the model still underestimated spring EPA concentrations in 2008 (Fig. 4). However, the significant negative predictor depth indicates that a depth-related effect on EPA concentrations exists, such that EPA concentrations in the greater depth $(8-20 \mathrm{~m})$ were always lower than in the upper water layer $(0-8 \mathrm{~m})$ even when mean temperature was considered in the model. To investigate this depth effect more closely, we introduced the deviations of temperature and light intensity from the mean values as variables in a third approach. The single predictor temperature deviation correlated significantly positive with EPA concentrations, while the predictive power of the variable light deviation was low as it was not present in the best models. The variable mean light intensity as a single predictor was significant with positive sign in all the best models, which is the opposite result from the second approach, suggesting that light availability influences the EPA concentrations of plankton seasonally. Mean temperature had no significant effect on EPA concentrations. The positive signs of the predictors temperature deviation and mean light intensity contrast with laboratory findings that algal EPA concentrations are usually lower at high temperatures and high light intensities (Thompson et al., 1990; Blanchemain \& Grizeau, 1996; Piepho et al., 2012). This suggests that these positive effects may not reflect direct causal mechanisms but probably include potential covarying factors that are not explicitly considered in the model and that the variables we have chosen cannot explain the depth-related differences in EPA concentrations.

However, in accordance with studies of EPA concentration in algae at different light intensities (Thompson et al., 1990; Blanchemain \& Grizeau, 1996), we found that the negative interaction term between diatoms and mean light is an important predictor of EPA concentrations. This term indicates that at a low mean light intensity, an increase in diatom biomass results in a greater increase in EPA concentration compared to the same biomass increase at high light conditions (Fig. 5a). The significant negative interaction term between ciliates and temperature deviation indicates that at lower temperatures (8-20 m; negative temperature deviations), an increase in ciliate biomass leads to a greater increase in EPA concentration compared to the same biomass increase at high temperatures (0-8 m; positive temperature deviations; Fig. 5b). This is in accordance with the study by Nozawa \& Thompson (1979) who found that ciliates adjust their fatty acid composition to changing temperatures.

In conclusion, this third approach could not sufficiently explain the depth-related differences in EPA concentrations that our second approach revealed. We partly found contradictory effects of the abiotic variables that were the opposite of our results in the second approach and counterintuitive to results from laboratory experiments. Therefore, the model outcomes of this third approach appear not to be reliable estimates of EPA concentrations.

In earlier years, fatty acids were usually not measured but detailed information on plankton biomass and composition is available for many well-studied lakes (Anneville et al., 2005; Dokulil \& Teubner, 2005; Jeppesen et al., 2005). Our results show that these data may enable an estimate of EPA concentrations, as the estimated EPA concentrations in 1997 with our models correlated significantly with the measured values. It has to be considered that in 1997 the sampling site for EPA measurements (Wacker \& Von Elert, 2001) differed from that for plankton, temperature and light which were measured at the same site as in the present study. Furthermore, samples for EPA measurements in 1997 were taken from $6 \mathrm{~m}$ depth, while the measurements of the predictive variables were pooled for $0-8 \mathrm{~m}$. Nevertheless, our biomass model estimates explained $80 \%$ of the variability of the measured EPA concentrations in Lake Constance 
seston in 1997 (Fig. 6) and the best model from the second approach that additionally included mean temperature and depth explained $87 \%$ of the variability, despite the above-mentioned differences in sampling.

We have demonstrated that it is possible to use the biomass of plankton organisms to estimate EPA concentrations in lake seston. Furthermore, our study emphasises the importance of ciliates as a potential EPA source (regardless of whether they contribute EPA by de novo synthesis or by repackaging from their diets). Including mean temperature or light and the deviations from the mean values improved the correlation between measured and estimated EPA concentration in 2008/2009, even when accounting for the additional variables. This is in accordance with laboratory findings that these abiotic variables influence EPA concentrations of plankton organisms. However, the sign of the mean light effect and temperature deviation effect was the opposite of the expected value. This suggests that the correlation between temperature and light, and EPA concentrations in 2008/2009 may not exclusively reflect direct causal mechanisms generalizable across years but includes potential covarying factors that are not explicitly considered in the model, and emphasises the problems of transferring laboratory results to the often much more complex field conditions. The biotic predictors explained most of the variability of EPA concentrations, and considering the controversial effects of the abiotic variables, the pure biomass approach seems to be the more useful alternative. Furthermore, not all long-term data sets from other well-studied lakes with sufficient biomass data will be depth-resolved or have extensive measurements of abiotic factors. Therefore, for a hindcast of EPA concentrations to test for constraints on consumers such as daphnids, a biomass model would be sufficient.

\section{Acknowledgments}

We thank B. Beck, S. Donath, F. Fornoff, Dr. S. SchmidtHalewicz, Ch. Gebauer, S. Heim, P. Mahler, P. Merkel, M. Piepho and G. Richter for excellent technical assistance and F. de Castro for helpful comments on the manuscript. Onur Kerimoglu calculated water column light availability from irradiances, which were provided by the German National Meteorological Service, Deutscher Wetterdienst, and from measured chlorophyll- $a$ profiles. Temperature data were provided by Frank Peeters. We acknowledge the valuable comments of two reviewers. This study was supported by the German Research Foundation (DFG RO 1008/12-1 and WA 2445/4-1).

\section{References}

Ahlgren G., Gustafsson I.B. \& Broberg M. (1992) Fatty acid content and chemical composition of freshwater microalgae. Journal of Phycology, 28, 37-50.

Ahlgren G., Lundstedt L., Brett M. \& Forsberg C. (1990) Lipid composition and food quality for some fresh water phytoplankton for cladoceran zooplankters. Journal of Plankton Research, 12, 809-818.

Anneville O., Gammeter S. \& Straile D. (2005) Phosphorus decrease and climate variability: mediators of synchrony in phytoplankton changes among European peri-alpine lakes. Freshwater Biology, 50, 1731-1746.

Beach D.H., Harrington G.W. \& Holz .G.G. Jr (1970) The polyunsaturated fatty acids of marine and freshwater cryptomonads. Journal of Protozoology, 17, 501-510.

Bec A., Desvilettes C., Véra A., Fontvieille D. \& Bourdier G. (2003) Nutritional value of different food sources for the benthic Daphnidae Simocephalus vetulus: role of fatty acids. Archiv für Hydrobiologie, 156, 145-163.

Bec A., Perga M.-E., Desvilettes C. \& Bourdier G. (2010) How well can the fatty acid content of lake seston be predicted from its taxonomic composition? Freshwater Biology, 55, 1958-1972.

Beenakkers A.M.T., Van der Horst D.J. \& Van Marrewijk W.J.A. (1985) Insect lipids and lipoproteins, and their physiological processes. Progress in Lipid Research, 24, 19-67.

Blanchemain A. \& Grizeau D. (1996) Eicosapentaenoic acid content of Skeletonema costatum as a function of growth and irradiance; relation with chlorophyll a content and photosynthetic capacity. Journal of Experimental Marine Biology and Ecology, 196, 177-188.

Boëchat I.G. \& Adrian R. (2005) Biochemical composition of algivorous freshwater ciliates: you are not what you eat. FEMS Microbiology Ecology, 53, 393-400.

Bolker B.M. (2008) Ecological Models and Data in R. Princeton University Press, Princeton.

Brett M.T., Müller-Navarra D.C. \& Park S. (2000) Empirical analysis of the effect of phosphorus limitation on algal food quality for freshwater zooplankton. Limnology and Oceanography, 45, 1564-1575.

Burnham K.P. \& Anderson D.R. (1998) Model Selection and Inference - A Practical Information-Theoretic Approach. Springer, New York.

Burns C.W. (1968) The relationship of body size of filterfeeding Cladocera and the maximum size of particles ingested. Limnology and Oceanography, 13, 675-678.

Chu F.-L.E., Lund E.D., Littreal P.R., Ruck K.E. \& Harvey E. (2009) Species-specific differences in long-chain n-3 essential fatty acids, sterol, and steroidal ketone production in six heterotrophic protist species. Aquatic Biology, 6, 159172.

DeBiase A.E., Sanders R.W. \& Porter K.G. (1990) Relative nutritional value of ciliate protozoa and algae as food for Daphnia. Microbial Ecology, 19, 199-210. 
Desvilettes C. \& Bec A. (2009) Formation and transfer of fatty acids in aquatic microbial food webs: role of heterotrophic protists. In: Lipids in Aquatic Ecosystems. Springer, New York.

Desvilettes C., Bourdier G., Amblard C. \& Barth B. (1997) Use of fatty acids for the assessment of zooplankton grazing on bacteria, protozoans and microalgae. Freshwater Biology, 38, 629-637.

Dokulil M.T. \& Teubner K. (2005) Do phytoplankton communities correctly track trophic changes? An assessment using directly measured and paleolimnological data. Freshwater Biology, 50, 1594-1604.

Gaedke U. (1992) The size distribution of plankton biomass in a large lake and its seasonal variability. Limnology and Oceanography, 37, 1202-1220.

Gladyshev M.I., Sushchik N.N., Makhutova O.N., Dubovskaya O.P., Kravchuk E.S., Kalachova G.S. et al. (2010) Correlations between fatty acid composition of seston and zooplankton and effects of environmental parameters in a eutrophic Siberian reservoir. Limnologica, 40, 343-357.

Greenberg A.E., Trussel R.R. \& Clesceri L.S., Eds (1985) Standard Methods for the Examination of Water and Wastewater. American Public Health Association, Washington, DC.

Hartwich M., Martin-Creuzburg D., Rothhaupt K.O. \& Wacker A. (2012) Oligotrophication of a large, deep lake alters food quantity and quality constraints at the primary producer-consumer interface. Oikos, doi: 10.1111/j.16000706.2011.20461.x.

Harvey H.R., Ederington M.C. \& McManus G.B. (1997) Lipid composition of the marine ciliates Pleuronema sp. and Fabrea salina: shifts in response to changes in diet. Journal of Eukaryotic Microbiology, 44, 189-193.

Internationale Gewässerschutzkommission für den Bodensee (2008) Jahresbericht der Internationalen Gewässerschutzkommission für den Bodensee: Limnologischer Zustand des Bodensees Nr. 36. Langenargen, Germany.

Jeppesen E., Sondergaard M., Jensen J.P., Havens K.E., Anneville O., Carvalho L. et al. (2005) Lake responses to reduced nutrient loading - an analysis of contemporary long-term data from 35 case studies. Freshwater Biology, 50, 1747-1771.

Johnson J.B. \& Omland K.S. (2004) Model selection in ecology and evolution. TRENDS in Ecology and Evolution, 19, 101108.

Jürgens K., Skibbe O. \& Jeppesen E. (1999) Impact of metazooplankton on the composition and population dynamics of planktonic ciliates in a shallow, hypertrophic lake. Aquatic Microbial Ecology, 17, 61-75.

Kainz M., Arts M.T. \& Mazumder A. (2004) Essential fatty acids in the planktonic food web and their ecological role for higher trophic levels. Limnology and Oceanography, 49, 1784-1793.

Kainz M.J., Perga M.-E., Arts M.T. \& Mazumder A. (2009) Essential fatty acid concentrations of different seston sizes and zooplankton: a field study of monomictic coastal lakes. Journal of Plankton Research, 31, 635-645.

Kamjunke N., Straile D. \& Gaedke U. (2009) Response of heterotrophic bacteria, autotrophic picoplankton and heterotrophic nanoflagellates to re-oligotrophication. Journal of Plankton Research, 31, 899-907.

Klein Breteler W.C.M., Koski M. \& Rampen S. (2004) Role of essential lipids in copepod nutrition: no evidence for trophic upgrading of food quality by a marine ciliate. Marine Ecology Progress Series, 274, 199-208.

Klein Breteler W.C.M., Schogt N., Baas M., Schouten S. \& Kraay G.W. (1999) Trophic upgrading of food quality by protozoans enhancing copepod growth: role of essential lipids. Marine Biology, 135, 191-198.

Lundstedt L. \& Brett M.T. (1991) Differential growth rates of three cladoceran species in response to mono- and mixed-algal cultures. Limnology and Oceanography, 36, 159-165.

Marchessault P. \& Mazumder A. (1997) Grazer and nutrient impacts on epilimnetic ciliate communities. Limnology and Oceanography, 42, 893-900.

Martin-Creuzburg D., Bec A. \& von Elert E. (2005) Trophic upgrading of picocyanobacterial carbon by ciliates for nutrition of Daphnia magna. Aquatic Microbial Ecology, 41, 271-280.

Müller-Navarra D.C. (1995a) Evidence that a highly unsaturated fatty acid limits Daphnia growth in nature. Archiv für Hydrobiologie, 132, 297-307.

Müller-Navarra D.C. (1995b) Biochemical versus mineral limitation in Daphnia. Limnology and Oceanography, 40, 1209-1214.

Müller-Navarra D.C., Brett M.T., Park S., Chandra S., Ballantyne A.P., Zorita E. et al. (2004) Unsaturated fatty acid content in seston and tropho-dynamic coupling in lakes. Nature, 427, 69-72.

Müller-Navarra D.C. \& Lampert W. (1996) Seasonal patterns of food limitation in Daphnia galeata: separating food quantity and food quality effects. Journal of Plankton Research, 18, 1137-1157.

Nozawa Y. \& Thompson G.A. (1979) Lipids and membrane organization in Tetrahymena. In: Biochemistry and Physiology of Protozoa (Eds. Levandowski M. \& Hutner S.H.), pp. 276335. New York Academic Press, New York.

Peeters F., Straile D., Lorke A. \& Ollinger D. (2007) Turbulent mixing and phytoplankton spring bloom development in a deep lake. Limnology and Oceanography, 52, 286-298.

Piepho M., Arts M.T. \& Wacker A. (2012) Species-specific variation in fatty acids concentrations of four phytoplankton species: does phosphorus supply influence the effect of light intensity or temperature? Journal of Phycology, 48, 64-73.

Reuss N. \& Poulsen L.K. (2002) Evaluation of fatty acids as biomarkers for a natural plankton community. A field 
study of a spring bloom and a post-bloom period off West Greenland. Marine Biology, 141, 423-434.

Sperfeld E. \& Wacker A. (2011) Temperature and cholesterol induced changes in eicosapentaenoic acid limitation of Daphnia magna determined by a promising method to estimate growth saturation thresholds. Limnology and Oceanography, 56, 1273-1284.

Sushchik N.N., Gladyshev M.I., Kalachova G.S., Kravchuk E.S., Dubovskaya O.P. \& Ivanova E.A. (2003) Particulate fatty acids in two small Siberian reservoirs dominated by different groups of phytoplankton. Freshwater Biology, 48, 394-403.

Sushchik N.N., Gladyshev M.I., Makhutova O.N., Kalachova G.S., Kravchuk E.S. \& Ivanova E.A. (2004) Associating particulate essential fatty acids of the w3 family with phytoplankton species composition in a Siberian reservoir. Freshwater Biology, 49, 1206-1219.

Taipale S., Kankaala P., Hämäläinen H. \& Jones R.I. (2009) Seasonal shifts in the diet of lake zooplankton revealed by phospholipid fatty acid analysis. Freshwater Biology, 54, 90104.

Thompson P.A., Harrison P.J. \& Whyte J.N.C. (1990) Influence of irradiance on the fatty acid composition of phytoplankton. Journal of Phycology, 26, 278-288.

Viso A.-C. \& Marty J.-C. (1993) Fatty acids from 28 marine microalgae. Phytochemistry, 34, 1521-1533.

Von Elert E. (2002) Determination of limiting polyunsaturated fatty acids in Daphnia galeata using a new method to enrich food algae with single fatty acids. Limnology and Oceanography, 47, 1764-1773.

Wacker A. \& Martin-Creuzburg D. (2007) Allocation of essential lipids in Daphnia magna during exposure to poor food quality. Functional Ecology, 21, 738-747.

Wacker A. \& Von Elert E. (2001) Polyunsaturated fatty acids: evidence for non-substitutable biochemical resources in Daphnia galeata. Ecology, 82, 2507-2520.

Wacker A. \& Weithoff G. (2009) Carbon assimilation mode in mixotrophs and the fatty acid composition of their rotifer consumers. Freshwater Biology, 54, 2189-2199.
Wickham S.A., Gilbert J.J. \& Berninger U.G. (1993) Effects of rotifers and ciliates on the growth and survival of Daphnia. Journal of Plankton Research, 15, 317-334.

Zhukova N.V. \& Kharlamenko V.I. (1999) Sources of essential fatty acids in the marine microbial loop. Aquatic Microbial Ecology, 17, 153-157.

Zöllner E., Santer B., Boersma M., Hoppe H.G. \& Jürgens K. (2003) Cascading predation effects of Daphnia and copepods on microbial food web components. Freshwater Biology, 48, 2174-2193.

\section{Supporting Information}

Additional Supporting Information may be found in the online version of this article:

Table S1. Results of the first model approach including all parameters of the variables ciliates, diatoms, cryptophytes and other phytoplankton groups.

Table S2. Results of the second model approach including all parameters of the variables ciliates, diatoms, cryptophytes, other phytoplankton groups, mean light intensity, mean temperature, depth and mean phosphorus concentration.

Table S3. Results of the third model approach including all parameters of the variables (ciliates, diatoms, cryptophytes, other phytoplankton groups, mean light intensity, mean temperature and deviations of light and temperature from the mean values) and interaction terms.

As a service to our authors and readers, this journal provides supporting information supplied by the authors. Such materials are peer-reviewed and may be re-organized for online delivery, but are not copy-edited or typeset. Technical support issues arising from supporting information (other than missing files) should be addressed to the authors.

(Manuscript accepted 2 April 2012) 